УДК 371

\title{
ОРГАНИЗАЦИЯ ПРЕДМЕТНО-ПРОСТРАНСТВЕННОЙ СРЕДЫ ДЛЯ ВСЕХ УЧАСТНИКОВ ОБРАЗОВАТЕЛЬНОГО ПРОЦЕССА ПРИ ФОРМИРОВАНИИ КОНКУРЕНТОСПОСОБНОЙ И СОЦИАЛЬНО-АКТИВНОЙ ЛИЧНОСТИ В РАМКАХ ЭКСПЕРИМЕНТАЛЬНОЙ ПЛОЩАДКИ
}

\author{
Чингизов Фанзиль Фаизович \\ Почетный работник общего образования РФ, \\ руководитель экспериментальной площадки \\ ФГБНУ ИСРО РАО \\ Кусябаева Миляуша Амировна \\ директор \\ Яркова Татьяна Сергеевна \\ заместитель директора по НМР \\ МОБУ СОШ д. Кабаково
}

Аннотация: В статье предложены и охарактеризованы пути формирования конкурентоспособной и социально-активной личности учащихся, раскрыта работа по данному направлению с педагогами и родителями, показана модель эффективного взаимодействия «Школа-ВУЗ» при сопровождении профессионального самоопределения обучающихся, совокупность реализации направлений, которые позволяют достичь необходимых результатов.

Ключевые слова: предметно-пространственная среда, конкурентоспособная личность, социально-активная личность, сетевое взаимодействие, профессиональное самоопределение.

Abstract: The article offers and describes the ways of forming a competitive and socially active personality of students, outlined the work in this area with teachers and with parents, shows the model of effective interaction between "School - University" that helps in self - determination of students, shows the set of realizations in these areas that lead to required results.

Key words: spatial development, competitive personality, socially active personality, network interaction, professional self - determination. 
Образование и воспитание выполняют важную общественную функцию - формируют самосознание человека. Образование выступает фактором воспроизводства социально-профессиональной структуры общества. Система образования воспитывая гражданина, тем самым оказывает воздействие на политическую и экономическую сферы общественной жизни.

Одной из основных задач образовательной политики на современном этапе становится развитие конкурентоспособности личности, ее соответствия актуальным и перспективным потребностям образования, общества и государства.

Что скрывает под собой понятие «конкурентоспособная личность»? Изучив и проанализировав научно-педагогическую литературу по подходам к определению понятия «конкурентоспособная личность» и понимая под ней совокупность свойств и особенностей личности, с помощью которых сформирована способность максимально расширить собственные возможности, логически напрашивается следующий вопрос: «Какими умениями и навыками должен обладать учитель образовательного учреждения, чтобы сформировать конкурентоспособную личность и как выстроить организационно педагогическую модель сопровождения профессионального самоопределения обучающихся?» Многие педагогиисследователи понимают невозможность формирования конкурентоспособной личности учителями, которые не обладают этими же качествами. Следовательно, для педагогического состава необходимо создать такие условия, которые способствовали бы развитию необходимого набора качеств для реализации поставленной цели, а именно: формировать социальную активность педагогов, вовлекать педагогов в системную научноисследовательскую, публицистическую и грантовую деятельность, проведение тренингов с педагогами, выявление и своевременное устранение компетентностных проблем педагогов и т.д. Но помимо учащихся и педагогов в образовательном процессе есть еще один участник- родитель (законный представитель ребенка), который так же должен быть заинтересован и готов принять участие в совместной работе по формированию конкурентоспособной личности. Но будет ли конкурентоспособность полноценной без профессионального самоопределения обучающегося? Направления были обозначены, цель и задачи были сформированы и на основании этого была составлена модель 
предметно-пространственной среды и профессионального самоопределения обучающегося (рис.1):

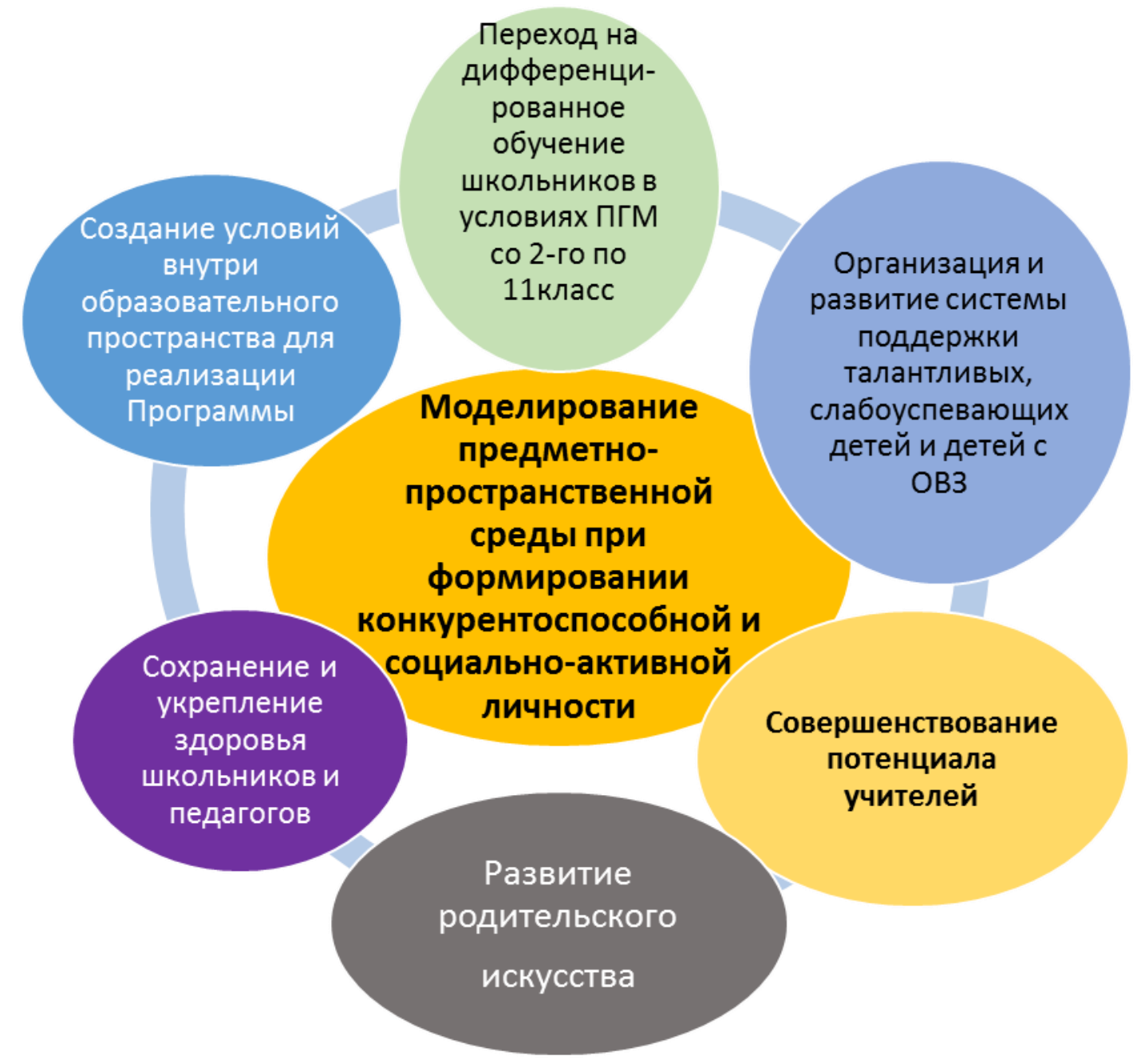

Рис. 1. Моделирование предметно-пространственной среды

Таким образом, мы выделили шесть основных направлений и приступили к реализации поставленных задач по каждому из направлений в рамках экспериментальной площадки ФГБНУ ИСРО РАО.

Каждое направление имеет свои траектории реализации, все они решают частные задачи и дополняют друг друга, реализуя одну цель: Формирование конкурентоспособной и социально-активной личности.

Переход на дифференцированное обучение школьников в условиях поточно-группового метода (рис.2).

Для создания оптимальных условий развития каждого школьника в том числе и детей с ОВ3 является принцип учёта индивидуальных особенностей ребёнка. Последовательная реализация дифференцированного подхода к 
каждому ученику нейтрализует все негативные последствия традиционного обучения. Создавать условия использования фактических и потенциальных возможностей каждого ребёнка возможно при внедрении в учебный процесс поточно-группового метода обучения (далее-ПГМО). Инициативной группой специалистов в рамках федеральной экспериментальной площадки ФГБНУ ИСРО РАО под руководством профессора Т.Ю. Ломакиной была разработана Программа «Концепция дифференцированного обучения школьников в условиях поточно-группового метода». Экспериментальная площадка функционирует на базе МОБУ СОШ д. Кабаково Кармаскалинского района и включает в себя три траектории:

1. Внедрение дифференцированного подхода при изучении иностранных языков ПГМО в начальной школе;

2. Внедрение дифференцированного обучения школьников в условиях ПГМО в среднем звене;

3. Реализация предпрофильной подготовки учащихся (сетевое взаимодействие).

Основная задача - повысить эффективность образовательного процесса, благодаря внедрению в образовательные учреждения концепции дифференцированного обучения школьников в условиях ПГМО

Переход на дифференцированное обучение школьников в условиях ПГМ

Реализация предпрофильной подготовки учащихся с 8-го по 11 класс
Реализация дифференцированного обучения английскому и башкирскому языку учащихся начальной школы в условиях ПГМ

\section{Реализация} дифференцированного обучения школьников с 5го по 11 класс в условиях ПГМ

\section{Рис. 2. Переход на дифференцированное обучение}




\section{Теоретико-методологический}

анализ

исследования

проблемы

дифференцированного обучения в ПГМО младшего и среднего звена позволил разработать и апробировать психолого-педагогическую концепцию включающую комплекс научно-практических методик и рекомендаций для заинтересованных специалистов.

Критерии оценки ожидаемых результатов:

-положительная динамика результатов работы

-динамика результатов участия на олимпиадах, конференциях различного уровня;

-повышение мотивации детей к обучению в школе.

Управленческие способы достижения результата:

- подбор педагогов-новаторов и научного руководителя;

-своевременные срезы результатов исследования (входные, промежуточные и итоговые), их обработка;

-ежегодные отчеты о ходе исследований.

Реализация дифференцированного подхода при изучении языков в начальной школе основано на исследованиях психологов, которые выяснили, что младший школьный возраст (6-11 лет) является наиболее благоприятным для овладения иностранным языком. Именно в этом возрасте еще мало штампов речевого поведения, легко по-новому “кодировать” свои мысли, нет больших трудностей при вступлении в контакт на иностранном языке. Когда методическая система построена достаточно грамотно с лингводидактической и психолингвистической точки зрения, то успех в овладении предлагаемым ограниченным языковым материалом и создание необходимых предпосылок для дальнейшего усвоения любого иностранного языка обеспечен практически всем детям.

Способности к изучению языка не одинаковы: одним язык даётся легко, другим - с большим трудом. Учебный материал на разных ступенях обучения может усваиваться учащимися одного и того же возраста по-разному: одни легче усваивают лексику, в силу хорошо развитой механической памяти, у других более развито слуховое восприятие, поэтому они успешно справляются с заданиями по аудированию и т. д. Кроме того у всех детей разный склад мышления. Изучение интересов и склонностей учащихся, их учебных возможностей, а также анализ перспектив развития этих возможностей должны послужить исходным моментом в дифференцированном подходе к обучению языкам и как следствие 
формирования прочной языковой базы.

Для реализации направления дифференцированного подхода при изучении иностранного языка в начальной школе, инициативной группой специалистов на базе экспериментальной площадки Бирского филиала федерального государственного бюджетного образовательного учреждения высшего образования «Башкирский государственный университет» под руководством Улыбиной О.В. была разработана Программа. Преимуществом программы является использование психологической индивидуальности каждого школьника, в том числе с ОВ3 как ключ (механизм) успеха и повышения уровня языковой подготовки учащихся. $\mathrm{C}$ учетом индивидуальных различий и дифференцированного подхода, дети распределены на группы по степеням усвоения русского, башкирского и английского языков. Программа разработана на основе многолетнего теоретического анализа и практического опыта по трём моделям обучения: коррекционной, традиционной и оснащенной. Обобщение психологопедагогического опыта дало возможность разработать модель исследования и выявить механизмы, устраняющие недостатки и противоречия в дифференциальном обучении младших школьников. В целом, разработанная концепция обеспечивает повышение эффективности образовательного процесса и дает возможность сформировать языковую базу и повысить эффективность усвоения языков в среднем и старшем звеньях.

Воплощая современные тенденции в жизнь по траектории профессионального самоопределения учащихся рабочей группой экспериментальной площадки, было принято решение о создании единого образовательного пространства в системе «Школа-ВУЗ» по аграрному направлению и Школа МВД-Школа по кадетскому направлению. Двумя сторонами ( БГАУ- далее Университет и МОБУ СОШ д. Кабаково-далее Школа) в октябре 2019 году было заключено Соглашение , предметом которого является развитие перспективных направлений сотрудничества между Университетом и Школой в области образования, науки, разработки и реализации дополнительных профессиональных образовательных программ, направленных на удовлетворение потребностей Школы в подготовке обучающихся и в повышении квалификации педагогов; при внедрении в Школу новых технологий, научных разработок, проектов; по вопросам организации практик и стажировок обучающихся Школы в Университете. 
Основными целями сотрудничества между Университетом и Школой является установление долгосрочных связей по вопросам

подготовки учащихся, отвечающих требованиям и специфике современных предприятий и организаций;

внедрения инновационных достижений науки и техники в учебный процесс;

совместного развития новых комплексных направлений научных исследований, модернизации и диверсификации направлений подготовки высококвалифицированных специалистов в системе дополнительного образования, развития академической мобильности, развития инновационных форм взаимодействия и осуществления интеграции профессионального образования, науки и бизнес-структур;

совместного осуществления инновационной деятельности в образовательной, научной и практических сферах;

координации и организации взаимодействия по использованию и развитию современных технологий и научных достижений в образовании, производстве и сфере услуг;

установления устойчивых партнерских взаимоотношений между Сторонами по вопросам организации стажировок учащихся.

Для достижения целей были выделены и начали реализовываться на базе МОБУ СОШ д.Кабаково Кармаскалинского района Республики Башкортостан основные направления сотрудничества:

1 Внедрение предпрофессиональной подготовки и профильного обучения в Школе с 5 по 10 класс. После подписания Соглашения, на классных часах и родительских собраниях учащиеся и родители были ознакомлены с формами работы Школа-ВУЗ. На выбор им были предложены для ознакомления ряд рабочих профессий, и макет заявления для выбора и зачисления на курс.

2 Совместная разработка интегрированных планов и программ, обеспечивающих углубленное обучение учащихся в области естественнонаучных дисциплин: математики, биологии, химии, физики; Преподаватели ВУЗа разработали и утвердили программы работы с учащимися аграрных классов с 5 по 10 класс.

3 Развитие и совершенствование проектной и исследовательской работы с учащимися Школы; В ноябре 2019 года преподаватель БГАУ и учащийся 8 класса приступили к реализации совместного научного проекта, результат которого будет представлен в текущем учебном году на научной 
конференции. В 2020 г. Учащиеся 5 класса (аграрного класса) на районной Научно-практической конференции, заняли первое место и вышли на республиканский уровень.

4 Совместное проведение мероприятий для учащихся и педагогов; Благодаря помощи БГАУ в 2019 году был проведен 30 летний юбилей Школы.

5 Подготовка учащихся по дополнительным профессиональным образовательным программам, результатом которых будет получения удостоверения о наличии рабочей специальности.

6 Организация встреч обучающихся с представителями Университета из числа среднего и высшего руководящего состава, проведение мастерклассов представителями Университета; Неоднократно учащиеся и родители МОБУ СОШ д. Кабаково выезжали в Университет на экскурсии, мастер классы и деловые встречи.

7 Организация и проведение выездов в каникулярное время обучающихся в Университет с целью углубленного обучения по общеобразовательным предметам: биология, физика, химия, математика , а также проведение теоретических и практических занятий с обучающимися по специальностям дополнительного образования; В весенние каникулы 20182019 учебного года, учашиеся 8,10 классов выезжали на три дня с проживанием в БГаУ, для наших учащихся Школы было организованно бесплатное проживание и выделен весь отдельный этаж общежития, организовано бесплатное трех разовое питание, предоставлен бассейн и тренажерный зал. После завтрака дети занимались на теоретических занятиях, после обеда они разбивались на группы и расходились на практические занятия по ранее выбранным направлениям.

8 Организация и проведение стажировок учащихся и педагогов Школы в Университете;

9 Совместная деятельность по организации и проведению тематических конкурсов и мероприятий; Участие в олимпиадах ВУЗа, а в частности АГРО НИИ.

Ежегодно, до 1 июня, согласовываются с Университетом план сотрудничества на следующий учебный год.

Ежегодно, до 1 октября, предоставляются для защиты в Университет отчеты по основным направлениям сотрудничества за прошедший учебный год. 
По второму направлению «Организация и развитие системы поддержки талантливых, слабоуспевающих и детей с ОВ3» ведется следующая работа:а) введены новые кружки: мини футбол, спортивный туризм, военное дело (для кадетского класса), волейбол, баскетбол, Куряш (национальная борьба), для старшеклассников от БГПУ на бесплатной основе проводится кружок «машины Голдберга».б) 1 раз в неделю в МОБУ СОШ д. Кабаково и МОБУ Гимназии с. Кармаскалы приезжали преподаватели БГПУ им. Акмуллы и проводили «Робототехнику» для детей начальной школы, а так же подготавливали учащихся 8-11 классов к итоговой аттестации. По четвергам учащиеся Кармаскалинского района посещали выездные бесплатные занятия по математике «Математическая академия» на базе БГПУ в учебном корпусе 2.в) Благодаря совместной работе внутри ЭП с БГПУ, физико-математический факультет выделил преподавателя-тьютора технического направления. Данный преподаватель работает с учащимися над научными проектами.

Работа с детьми с ОВ3. Основная задача, помощь в социализации. Для этого 6.12.18 г. Внутри ЭП проводится мероприятие на базе МОБУ СОШ д.Кабаково для детей с ОВ3 «Подари мне солнце». В мероприятии будут приняли 30 учащихся с ОВ3 МОБУ СОШ д.Кабаково. Для них были проведены бесплатные Мастер-классы по «Робототехнике» с преподавателями БГПУ и «Рисование на воде-техника Эбру» от художественной школы «Мармелад».

Такая же активная работа велась и по другим направления площадки, в результате чего задачи были реализованы и цель частично достигнута. В настоящее время работа продолжается и планируется создание инновационной площадки, создание которой в современных условиях регламентируется и обеспечивается Федеральным законом №273 ст.20 ч.3,ч.4.

\section{Список литературы}

1. Т.Ю. Ломакина Социально-педагогические основы развития образовательных траекторий личности в системе непрерывного образования.М; Издательский Центр ИЭТ-2013.- С.185

2. А.М. Новиков Постиндустриальное образование- М. 2011.-С. 264

() Ф.Ф. Чингизов, М.А. Кусябаева, Т.С. Яркова, 2021 